\title{
FOLHETOS DE CORDEL NO ENSINO DE LÍNGUA : MATERNA: ASPECTOS CULTURAIS E FORMAÇÃO DOCENTE
}

\section{FOLHETOS DE CORDEL THE MOTHER TONGUE TEACHING: CULTURAL ASPECTS AND TEACHER TRAINING}

Linduarte Pereira Rodrigues(UEPB) ${ }^{1}$

\section{RESUMO}

Desde a antiguidade clássica, verifica-se uma poética da voz realizada a partir de diversas funções sociais ritualizadas pela palavra. Isso confirma uma tradição oral que persiste em nossos dias, agregada em vários aspectos do quotidiano (ZUMTHOR, 1993). A escrita nasce, então, como resposta às necessidades dos povos que narram a memória de sua gente e buscam, através dessas narrativas, a explicação e atualização da vida humana. Corroborando com tais assertivas, dados de pesquisas que venho desenvolvendo com gêneros textuais diversos das culturas populares, no campo das linguísticas aplicada e pragmática/discursiva, vêm demonstrando que os estudos do letramento são hoje um campo promissor de investigação e elaboração de métodos que buscam reunir pesquisas interessadas pela descrição e explicação da influência da oralidade e da escritura nas práticas culturais de sociedades letradas, o que contribui para a formação de professores de língua portuguesa empenhados na constituição de sujeitos escolares aptos para uma convivência sociocultural efetiva. Diante disso, destaca-se o fenômeno

1 É doutor em Linguística (UFPB)e professor-pesquisador do DLA e do PPGFP (UEPB). Grupos de pesquisa: Memória e Imaginário das Vozes e Escrituras (MIVE/ UFPB); Grupo de Estudos em Letramentos, Interação e Trabalho (GELIT/UFPB); Linguagem, interação e Gêneros Textuais/Discursivos (LITERGE/UEPB); Teorias do sentido: discursos e significações (TEOSSENO/UEPB). E-mail: linduarte. rodrigues@bol.com.br 
do letramento que extrapola o mundo da escrita e se interessa pela letra como prática sociocultural; o que permite fundamentar um estudo em diálogo com outros pesquisadores que compartilham com a ideia de um ensino de língua baseado em eventos e práticas de letramento, em que a voz antecede, atravessa e "finaliza" a produção escrita, animando o texto e atualizando discursos de um material regional típico do Nordeste: os folhetos de cordel brasileiros. Uma perspectiva de estudo que cobra a compreensão do lugar e do tempo que compõem o sujeito escrevente e falante, e/ou mesmo, que escreve para simular uma fala: ação dialógica e ideológica, marca de acontecimento sociocultural do homem na história.

PALAVRAS-CHAVE: Práticas culturais; Oral e escrito; Letramento; Folhetos de cordel.

\section{ABSTRACT}

Since classical antiquity, there is a poetic voice carried from various social functions ritualized by the word. This confirms an oral tradition that persists today aggregate in various aspects of daily life (ZUMTHOR, 1993). The writing is born, then, in response to the needs of people who narrate the memory of its people and seek, through these narratives, the explanation and update of human life. Corroborating such assertions, research data that I have developed with various genres of popular cultures in the field of applied and pragmatic/discursive language, have shown that literacy studies are now a promising field of research and development methods that seek to meet research interested in the description and explanation of the influence of orality and writing in cultural practices of literate societies, which contributes to the formation of Portuguese language teachers engaged in the creation of school subjects fit for effective socio-cultural coexistence. Therefore, there is the phenomenon of literacy that goes beyond the world of writing and are interested in the letter as socio-cultural practice; allowing support a study in dialogue with other researchers who share the idea of a language teaching based on events and literacy practices, crosses and "finish" the writing production, animating text and updating speeches a typical regional material Northeast: the Brazilian folhetos de cordel. 


\begin{abstract}
A study of perspective that charges the understanding of the place and time that make up the subject clerk and speaker, and/or even, who writes to simulate a speech: dialogical and ideological action, socio-cultural event mark of man in history.
\end{abstract}

KEYWORDS: Cultural practices; Oral and written; Literacy; Folhetos de cordel.

\title{
INTRODUÇÃO
}

No contexto atual, a Educação Nacional tem enfrentado inúmeros desafios para atingir objetivos positivos, em especial, no que diz respeito ao ensino-aprendizagem de linguagens. Como se existisse uma fórmula mágica para incluir o aluno nesse processo, por vezes, a metodologia empregada pelo professor de língua portuguesa é constantemente questionada. Com foco no ensino de língua portuguesa, este estudo pretende demonstrar que há mudanças sócio-históricas e teórico-aplicadas que alteram significantemente o ensino de linguagens.

Permeio minha fala a partir dos Parâmetros Curriculares Nacionais (BRASIL, 1998b, p. 127), especialmente no tocante a pluralidade cultural do povo brasileiro, material humano que compõe os bancos escolares da Educação Básica e para quem dedico meus estudos teórico-aplicados ao ensino de língua(gens) com a formação inicial e continuada de professores de língua portuguesa. $\mathrm{O}$ documento alerta para o fato de que a escola“"...] encontra-se marcada por práticas cultural e historicamente arraigadas, bem como por teorias que deslocaram a responsabilidade da escola para o aluno, além de currículos e formação de professores insuficientes”. Diante disso, sugere uma tomada de ação por parte dos intelectuais e docentes envolvidos com a escolarização nacional, a partir da adoção de "medidas estruturais" e do "estabelecimento de condições que revertam esse processo", o que inclui "o reconhecimento e valorização de características específicas e singulares de regiões, etnias, escolas, professores e alunos”.

Dentre as principais mudanças, e sobre a qual me debruço nas páginas seguintes, destaco a inclusão do sujeito escolar na história da materialidade textual utilizada como produto de linguagem que opera na cultura como prática social, o texto é sem dúvida meio e foco para a 
aula de língua portuguesa. Esta inclusão do texto, consequentemente do discurso e do sujeito que opera sentidos frente aos usos da linguagem, põe por terra o foco exclusivo na língua, considerada autossuficiente, como sustentava a Linguística Estrutural. Creio que situar o sujeito no centro das reflexões linguísticas significa hoje em dia voltar-se para o exterior da língua, para a produção sócio-histórico-cultural do texto e a atualização dos discursos que operam sentidos ideologicamente situados pela historicidade da palavra na sociedade e na cultura.

Este aspecto simbólico da palavra nos leva à consideração das condições de produção do texto e seus atravessamentos ideológicos e interdiscursivos. Com isso, tem-se agora um objeto complexo, pois dinâmico e heterogêneo,ao qual se apoia o professor para a atuação emsala de aula de língua portuguesa: o texto; e seu atualizador - o discurso. Este objeto multifacetado (texto/discurso) é produto da relação entre o sujeito, a história e a cultura; material que deve ser trabalhado no processo de ensino e aprendizagem da linguagem, levando em consideração que a flexibilidade educativa é forte forma de ação, uma vez que a mente encontra-se aberta a tornar significativas as atividades desenvolvidas pelo homem na história.Assim sendo, torna-se importante o trabalho em sala de aula com inúmeras práticas de letramento que permitem a constituição de práticas sociais legítimas no plano cultural, o que se dá através da diversidade de gêneros textuais, permitindo uma ação educativa voltada para a reflexão crítica do texto e do discurso, investimento docente que visa tornar a aprendizagem um instrumento a ser utilizado pelo sujeito nas diversas atividades de uso da linguagem.

Como apoio para despertar essa visão, destacam-se os folhetos de cordel produzidos e com circulação ativa no Nordeste brasileiro. Pretendo demonstrar que esse novo direcionamento permite que o processo de ensino-aprendizagem da linguagem seja repensado a partir da inclusão de novos objetos de estudo provenientes das culturas populares e que são inerentes à linguagem que é praticada e estudada/analisada na aula de língua portuguesa no Nordeste.Enfatizo a necessidade de se "[...] valorizar a ação de grupos, [...] dando voz a um passado que se faz presente em seres humanos que afirmam e reafirmam sua dignidade na herança cultural que carregam. Trata-se de ampliar o horizonte de referência do aluno, 
despertando sua curiosidade para o mundo que o cerca" (BRASIL/PCN, 1998b, p. 154).

Para tanto, parto da compreensão de que texto e discurso, sujeito e história são aspectos de uma sociologia da educação que permitem ao docente e seu alunado lançarem um olhar reflexivo/avaliativo/inventivo para as práticas discursivas que circulam no campo social das diversas culturas que compõem a nação brasileira e que se materializam de forma específica por intermédio da escrita e da oralidade, a exemplo dos folhetos de cordel.

Estas palavras iniciais permitem dirigir o meu discurso no sentido de relacionar os gêneros textuais como instrumentos para o ensino de língua(gens),o contexto de circulação e atuação dos folhetos de cordel que delineiam uma especificidade textual/discursiva de representação da diversidade cultural do povo nordestino e a possibilidade oferecida pelo cordel do desenvolvimento do letramento escolar, com ênfase na produção e no consumo de uma escritura vozeada.

\section{Gêneros textuais: instrumentos para o ensino de língua(gem)}

A aula de língua materna deve ser vista como um espaço que favorece a comunicação/interação dos membros da sociedade escolar, que propicia a formação crítica do cidadão e que realiza o ensino-aprendizagem da língua(gem), cujas bases devem ser o texto e o discurso. Mas para que de fato possamos construir esse perfil é necessária uma mudança na prática docente, é preciso que o professor amplie seus horizontes teóricos e passe a fazer uso de outros objetos culturais no ensino de linguagem, não se limitando, apenas, à língua e à gramática. Não basta apenas fazer atividades de leitura/compreensão de textos, se o foco do ensino permanecer a língua sob a perspectiva estruturalista. É preciso que aconteçam aulas planejadas e que a prática da leitura e reflexão da língua inclua: i) o papel do sujeito nos discursos; ii) o contexto sócio-histórico; iii) a retomada de discursos anteriores etc. Assim, é importante, nesse planejamento, definir o papel do professor como mediador, e o papel do aluno como coautor na construção dos conhecimentos postos em jogo na aula de língua portuguesa. 
Para tanto, faz-se necessário o trabalho com práticas linguísticodiscursivas próprias do cotidiano dos alunos, a fim de que estes possam refletir sobre suas atividades e atuações como sujeitos falantes/ouvintes, produtores e reprodutores de textos/discursos. Isso se dá pela compreensão da língua como fenômeno social, pois "A estrutura da enunciação e da atividade mental a exprimir são de natureza social. A elaboração estilística da enunciação é de natureza sociológica e a própria cadeia verbal, à qual se reduz em última análise a realidade da língua, é social. Cada elo dessa cadeia é social, assim como toda a dinâmica da sua evolução” (BAKHTIN/ VOLOSHINOV, 2002, p. 126).

À medida que Bakhtin/Voloshinov (2002) vincula a realidade da língua ao social ele também insere o sujeito nas reflexões linguísticas. $\mathrm{O}$ sujeito é posto no plano sociocultural da linguagem como um ser ativo, age na interação com o outro, traz para a língua a condição de funcionalidade e discursividade. Nesta perspectiva, toda atividade linguística está condicionada a uma interação, havendo sempre "um que diz" e outro "para quem se diz". Diante desse plano enunciativo, ao qual se inserem professores e alunos, sujeitos sociais ativos, destaco, dentre as diversas ações pedagógicas da atualidade, o trabalho com os gêneros textuais: importantes veículos comunicativos/interativos, portanto, apropriados para uma tomada de ação docente pautada por práticas de linguagem que se efetivam socioculturalmente no cotidiano das cidades.

Os novos atributos dirigidos aos gêneros textuais se devem a vários fatores, mas o principal deles são as mudanças crescentes no campo social que exigem cada vez mais do indivíduo o envolvimento com a letra. Sedo assim, não basta apenas ao sujeito decodificar signos, mas atribuir conhecimentos e nossos sentidos ao objeto lido, o que deveria ser uma constante em ambiente escolar. Diferentemente, a cultura educacional no Brasil, mesmo com as atuais mudanças nas concepções de ensino, ainda mantém fortemente enraizada uma predominância para os métodos tradicionais de tratamento da língua(gem) na escola. Esses fatores se devem a questões ideológicas propagadas desde as primeiras aulas ministradas pelos Jesuítas no Brasil Colônia. Na maioria das vezes, percebe-se que o trabalho com os gêneros textuais reflete um modismo ou mesmo se dá por imposição, de forma forçada, buscando-se atender aos ditames 
dos documentos oficiais, e também ao que é propagado pela imprensa : que detém a atenção de grande parte da massa educadora do país. Essa propagação de novos ideais de ensino é feita, muitas vezes, sem base segura e/ou eficiente da forma de como ministrar a aula de língua portuguesa, a partir da adoção do texto/discurso como objeto para o exame/reflexão da língua(gem). Assim, na grande maioria das vezes, os professores, perdidos em meio aos ensinamentos e orientações governamentais, acabam voltando aos velhos dogmas educacionais, em que a leitura do texto é prática invasiva para o tratamento tradicional da gramática normativa.

Os Parâmetros Curriculares Nacionais (BRASIL, 1998a) endossam como fator positivo no processo de ensino-aprendizagem da língua portuguesa a utilização de gêneros textuais diversos em atividades escolares. Considerados instrumentos de construção de sentido e interação social, com o auxílio deles os indivíduos se inter-relacionam por meio da linguagem em diversas situações comunicativas. Segundo o documento, "Um leitor competente é alguém que, por iniciativa própria, é capaz de selecionar, dentre os textos que circulam socialmente, aqueles que podem atender a uma necessidade sua. Que consegue utilizar estratégias de leitura adequada para abordá-los de forma a atender a essa necessidade" (BRASIL/ PCN, 1998a, p. 15).

A partir das orientações contidas nos documentos supracitados, destacoGeraldi (1997; 2010), que defende um trabalho de formação docente ancorado às demandas de letramentos da contemporaneidade. Para ele, cada região deve pensar em medidas específicas para o ensino de língua(gem) pautado pela inserção do texto na sala de aula (GERALDI, 1997), e em prol de um projeto, por exemplo, que atenda a região Nordeste, em que não se ignorariam as tradições orais de transmissão cultural da palavra (GERALDI, 2010). Considero que o cordel se impõe relevante frente ao postulado pelo autor. Os folhetos de cordel são expressões da cultura popular nordestina que representam modelos e estruturas socioculturais atrelados à tradição sociodiscursiva do Nordeste. Estudos recentes demonstram que este tipo de expressão popular tem se tornado fonte valiosa para pesquisas linguístico-literárias em ambientes acadêmicos (RODRIGUES, 2006; 2011), o foco agora se volta para a aplicabilidade de metodologias de ensino de língua portuguesa na Educação Básica. 
Corroboram para isso a diversidade de temas e a atualização dos discursos dessa materialidade textual que circulae garante a efetivaçãodas práticas : sociolinguísticas dos sujeitos dessa região do Brasil.

\section{Contexto de circulação e atuação dos folhetos de cordel}

Folhetos de feira, literatura popular e literatura de cordel são expressões que nomeiam um conjunto de textos produzido no nordeste brasileiro, material muito semelhante a um tipo de literatura que era encontrada comumente em Portugal. Segundo Cascudo (1988), na década de 60 houve a difusão do termo literatura de cordel no Brasil. Cascudo (1994) também chama essa literatura de brochurinhas em versos. O autor explica que não havia uma denominação genérica no Brasil para esse material impresso, afirmando-se, então, como literatura de cordel. Ele refere que isso se deu pelo fato de os "livrinhos" serem apresentados para a venda pendurados num barbante, como acontece ainda hoje em alguns pontos de venda do Brasil e em eventos folclóricos que buscam fazer referência a essa tradição.

Segundo Proença (1977), a literatura de cordel portuguesa se originou dos romances tradicionais daquela região da Europa. Impressos rudimentarmente em folhas soltas ou volantes e vendidos presos em um barbante ou cordel em feiras e romarias, traziam registros de fatos históricos, narrativas tradicionais como as da Imperatriz Porcina, Princesa Magalona e Carlos Magno, além de poesia erudita como as de Gil Vicente. Por esta razão, o cordel brasileiro estaria diretamente ligado, por sua origem, à literatura que foi trazida de Portugal para o Brasil pelos colonizadores e jesuítas, a partir do século XVI. Os folhetos também guardam uma relação dialógica com os chamados "bandos". Os atores desse evento de letramento

[...] percorriam a cavalo as ruas do Brasil antigo com tambores e cornetas, até parar em uma esquina onde um toque padrão, de corneta, se encarregava de atrair e reunir o público. Então, lia-se o bando, em pergaminho, versos que anunciavam um programa geral de festas populares [do Divino, por exemplo], tão populares, que tais programas continham invariavelmente em sua abertura críticas 
ferinas aos figurões e autoridades. Esse bando era 'folha volante', folheto [o pliego suelto], folha toda dobrada. [...] Tais modelos teriam evoluído para o folheto do Nordeste, 'anunciados' em 'pregões' nos postos de venda (PROENÇA, 1977, p.27).

Contudo, a relação entre a literatura de cordel portuguesa e o folheto de feira brasileiro, ou folheto de cordel, não é aceita igualmente entre os estudiosos. Há quem prefere associar a origem dos folhetos brasileiros a um tipo de poesia especificamente oral, como é o caso das pelejas e desafios que já existiam no nordeste brasileiro. Não descartando completamente a influência portuguesa, mas apegando-se à referência ao oral, Meyer (1980, p. 7) argumenta que o costume de contar histórias entre as famílias brasileiras, nas fazendas e nos engenhos do Nordeste, deve ter sido a razão do desenvolvimento desse tipo de literatura popular no Brasil:

Esse costume proveio de uma longa tradição ibérica, dos romanceiros, das histórias de Carlos Magno e os Doze Pares de França e outros grandes livros populares. Originou-se também de contos maravilhosos de 'varinha de condão', de bichos falantes, de bois - sobretudo na região nordestina, onde se desenvolveu o ciclo do gado; e, ainda de histórias do folclore universal e africano - estas trazidas pelos escravos, acostumados à narrativa oral em suas terras de origem.

Para Mayer (1980, p. 3-7), as histórias, naquela época, eram veiculadas por cantadores ambulantes. Eles iam de fazenda em fazenda e às feiras livres, transmitindo notícias de um lugar para outro, aproximando as pessoas: "Reproduziam histórias, inventando casos, improvisos, repentes, desafios e pelejas entre cantadores. [...] Contadores de história e cantadores de cantorias sempre estiveram associados ao mundo nordestino”. Esse processo se iniciou com o hábito de contar histórias e resultou, com a imprensa, nos folhetos de cordel. A autora explica que em todo o mundo, desde tempos imemoriais, a tradição da literatura escrita culta correspondeu sempreà tradição oral de contar histórias: “Às vezes, porém, o contador pegava lápis e papel e se punha a escrever - ou a ditar - o 
que já estava havia tempo em sua memória, ou o que de novo inventava, ampliando um pouco o seu público”.

Com o surgiram das máquinas impressoras, estendeu-se a divulgação dessas obras. Alguns folhetos eram escritos em prosa, mas a maioria era em versos, sendo mais fácil para um público analfabeto decorar versos lidos. É fato que "o folheto de cordel não circula apenas entre os que sabem ler, mas também entre os que não o sabem; e estes, às vezes, até em maior número"(BRANDÃO, 1990, p. 30). Esse fenômeno impõe ao cordelista facilitar para o público alvo de seus folhetos a leitura de suas produções e permite o interesse pelos folhetos de cordel por parte de uma clientela ampla de sujeitos que promovem o atravessamento dessa escritura vozeada em suas práticas de letramento.

Diante do exposto, saliento que essa tradição nordestina não pode ser ignorada pela escola.Em meus estudos, orientoa adoção desse material textual-literário como agente linguístico-discursivo que permite,no Nordeste, a assimilação e o atravessamento da letra na vida cotidiana, processo de letramento que não deve mais ser ignorado pelo professor que opera sentido frente aos materiais textuais que sustentam o seu fazer docente em aulas de língua portuguesa. Enfatizo que o cordel, das xilogravuras à escrita, oferece rico material para as pesquisas aplicadas ao ensino de língua materna: possui variado campo semântico com interpretações diversas, remetendo ao contexto sociocultural em que se insere. Os temas dessa expressão cultural/textual são variados, versando sobre religião, política, economia, etc. Dessa forma, santos, políticos, cangaceiros e acontecimentos são tratados de forma original e numa linguagem próxima da oralidade: clara e espontânea, assim como seu público.

A composição temática dos folhetos de cordel revela um conjunto de sentidos específicos, pertencentes a um grupo de indivíduos bastante característico que, entre outras coisas, sofre com angústias provindas de questões de subsistência - as longas estiagens e, consequentemente o êxodo rural; de religião - a fé e a devoção aos santos do cristianismo; e da moral - o conservadorismo exacerbado. Paralelamente, de suas conquistas, dos mitos e das personalidades como Silvino, Lampião, Padre Cícero, líderes políticos e artistas da TV etc. 
Batista (1977) divide o referido material textual em três grupos temáticos: i) Os gêneros tradicionais (romances, novelas, contos maravilhosos e heroicos, estórias de animais e da tradição religiosa);ii) Fatos circunstanciais ou acontecidos de natureza física (enchentes, secas, terremotos etc.), de repercussão social (festas, desportos, novelas etc.), cidade e vida urbana, crítica e sátira, elemento humano (figuras atuais ou atualizadas), o ciclo do fanatismo e misticismo, o ciclo do cangaceirismo etc.; iii) Cantorias e pelejas, que são poemas improvisados e recitados por dois poetas sobre temas diversificados.

Nesta perspectiva, Lima (2000) acentua que o cordel é uma das formas de expressão linguístico-cultural resultante de um vasto sistema de interferências no viver dos seus produtores, leitores e ouvintes, indivíduos quase sempre oriundos das camadas populares. Estes que constroem em suas poesias uma trama em que os símbolos de suas identidades estão amalgamados aos símbolos de suas experiências e trocas com as demais classes da sociedade.

Faz-se necessário destacar ainda que apesar da constante presença da oralidade nos textos que compõem a literatura de cordel, o material textual é necessariamente impresso, diferente de outras formas de poesia oral, como são as pelejas e desafios, que são cantados por cantadores e repentistas e, na maioria das vezes, são transmitidos de pessoa a pessoa, de cultura a cultura, sem nunca possuir registro escrito. No cordel, a memória do cordelista vem à tona a partir do recurso da escrita, suporte da voz no papel.Obviamente, a letra ganha vida mediante a decodificação textual, em que o ato de ler se confunde com o ato de falar. Aliás, essa é a intenção do poeta popular, espera que o público atribua valor a sua poética a partir de seu "dom" de "guardar memórias na cabeça".

No meio do povo e pela relação oral/escrito, o cordel se guardou e se tornou vivo até o fim do século XIX, tendo sobrevivido, mesmo com o surgimento da televisão e dos meios de comunicação mais modernos. Hoje há o consenso de que o cordel é um macrogênero textual de escritura vozeada (RODRIGUES, 2011), sendo esta "sua destinação gráfica, circulando em opúsculos impressos” (CASCUDO, 1988, p. 438). Nasceu em nossa cultura do embate entre lusitanos, indígenas e negros. Iniciouse pela oralidade e preserva suas origens, predominando a linguagem 
simples:traz consigo marcas da oralidade. Entretanto, sua materialidade é impressa, o que valida sua ação híbrida de imprimir sentido em sociedades que se construíram sócio-historicamente letradas mediante a tradição de escrever e falar, e mesmo escrever para simular uma fala.

Esse fenômeno é parte de nossa constituição sociolinguística no Nordeste e não deve ser mais ignorado pela escola. O cordel é veículo textual complexo e permite o desenvolvimento em nossos alunos da aprendizagem das quatro modalidades que constituem a atenção do professor de língua materna: ler, escrever, falar e analisar a língua.

\section{O cordel no letramento escolar: escritura e oralidade}

O fenômeno do letramento extrapola o mundo da escrita, tal qual ele é concebido pelas instituições de ensino, mas a escola ainda não se interessa gratuitamente pelo letramento como prática social, apenas, pelo letramento como imposição de uma tecnologia de códigos que se prestam para uma produção final: elaboração de textos com reprodução meramente escolar, sem nenhuma função social. A alfabetização tradicional é um exemplo dessa tecnologia que há tempos é prioridade no universo escolar, gerando a competência individual do sujeito de codificar e decodificar letras e números. Entretanto, ela não se mostra solução para o aperfeiçoamento do aluno como sujeito efetivamente letrado, competência sociocultural que extrapola o textual, atinge o discurso e as múltiplas formas de sua representação sociocultural e histórica.

Por esta razão, em meus estudos, apego-me à ideia subjacente aos teóricos que, a exemplo deKleiman (2001), sustentam que as práticas de letramento dominantes na escola são consideradas parciais e equivocadas. Denominadas de modelo autônomo de letramento, elas não são capazes de formar leitores culturalmente preparados para as diversas situações de interação entre sujeitos, indivíduos habilitados para a atuação frente à palavrafora dos muros da escola. Para o modelo autônomo de letramento, há apenas uma maneira de letrarque está diretamente associada ao progresso individual do sujeito, a sua civilização, tendo em vista a mobilidade social.

Do outro lado da corrente há um modelo de letramento que objetiva direcionar o educador para um trabalho de letramento voltado 
para práticas plurais de envolvimento do sujeito com a palavra:o modelo

: ideológico de letramento. Nele são plurais as formas assumidas pela escrita no domínio das instituições e nos contextos de produção, circulação e reprodução, em que a escrita atravessa as práticas socioculturais dos grupos e fundamenta suas relações. Segundo Kleiman (2001, p. 21), o modelo ideológico de letramento não pressupõe "uma relação causal entre letramento e progresso ou civilização, ou modernidade, pois, ao invés de conceber um grande divisor entre grupos orais e letrados, ele pressupõe a existência, e investiga as características de grandes áreas de interface entre práticas orais e práticas letradas". Diante disso, evidencio um processo de letramento em que

A linguagem oral, por sua vez, pressupõe a investigação das histórias orais em diferentes épocas e contextos, como transmissoras de uma determinada cultura, tendo em vista preservar e reinventar valores, normas e costumes no interior daquele grupo social. Daí a sua relevância para a configuração de nossa memória e identidade (BRASIL/ PCN, 1998b, p. 133-134).

Nesta perspectiva, Brito (1998) ressalta que não devemos pensar um universo em que a escrita se contrapõe à oralidade, figurando como formas independentes. Deve-se, é mais sensato, crer na multiplicidade de situações em que o saber letrado se inscreve com maior ou menor intensidade e grau de interferência. Para o autor, as pesquisas acerca dos processos de letramento demonstram que nas sociedades contemporâneas há um fluxo considerável de pessoas que, mesmo sendo analfabetas, possuem conhecimentos que permeiam a escrita e seu uso. Elas seutilizam deste conhecimento na realização de tarefas do cotidiano e demonstram que a palavra é algo fundamental para a vida urbana das sociedades industrializadas.

Dessa forma, cabe ao docente que atua com o ensino de língua(gem) "[...] oferecer informações e possibilitar reflexões sobre a língua materna, promover a compreensão de como se constituem identidades e singularidades de [...] linguagens presentes nas diversas regiões do Brasil" (BRASIL/PCN, 1998b, p. 133). Mas para que esse ideal se processe, 
professor e escola devem conceber a diversidade cultural e os letramentos que compõem e validam as práticas sociais dos sujeitos que frequentam o ambiente escolar, de forma que a aprendizagem da língua(gem) se efetive. Nesta perspectiva, proponho para o espaço escolar a interação verbal em que escrita e oralidade venham a ser encaradas como possibilidades de efetivação da linguagem pelos sujeitos e em ambiente social contínuo, sem divisas entre escola, igreja, família e demais instituições que operam os discursos por intermédio de gêneros textuais orais e escritos.

É fato que a modalidade escrita não se contrapõe ao oral, este é contínuo daquela num processo de atuação do homem em práticas sociais comunicativas/interativas; entretanto, há aspectos que favorecem um tipo de linguagem em um dado contexto de atuação sócio-histórica do sujeito e, por isso, há, nessa relação, a geraçãode níveis de linguagem que vão de um nível mais informal até um nível mais formal (os quais se encarregam a escola), havendo, claro, graus intermediários. Marcuschi (2001) assegura que o informal é uma das possibilidades de realização tanto da fala quanto da escrita. Contudo, esclareço que informal não quer dizer de menos valor ou sem prestígio. Há ocasiões, por exemplo, em que a fala é pretendida e o escrito é suporte para a memória, como em debates, discursos políticos e religiosos, nas aulas, teatro, televisão, rádio etc. Nesses contextos, os falantes buscam formas desprendidas do papel. Pretendem apresentar informalidade na ação enunciativa e para alcançarem o resultado pretendido, buscam escrever utilizando-se de recursos da fala. $\mathrm{O}$ produto dessa prática é uma escritura de tradição oral ou mesmo um texto que serve de suporte para a voz.

Um exemplo de escritura de tradição oral que ganha destaque no processo de letramento no Nordeste é o folheto de cordel. Segundo Abreu (1999, p. 74), a aproximação dos folhetos de cordel com as narrativas orais é parte "das estratégias de criação ou de adaptação de narrativas visando à assimilação dos folhetos por públicos não completamente familiarizados com a escrita”. A presença da oralidade na produção dos textos ocorre porque o poeta tradicional escreve como se estivesse contando histórias. Além do mais, este recurso facilita a leitura no momento da venda dos folhetos nas feiras livres, local onde ocorre a publicidade desses produtos 
: e que se resume em uma "leitura" 2 em voz alta, performática, de alguns : dos trechos que compõem a obra. "Nesse contexto, as imagens construídas pelos gestos, pelos sons, pela fala, pela plasticidade e pelo silêncio implicam conteúdos relevantes para a construção da identidade, pois é nesse universo plural de significados e sentidos que as pessoas se reconhecem na sua singularidade" (BRASIL/PCN, 1998b, p. 156). O destaque realizado nos PCN demonstra a relevância desse material textual/discursivo para uma atuação docente frente à linguagem em contexto em que essa mídia se insere naturalmente no dia a dia das cidades nordestinas.

O folheto de cordel possui laços aproximativos com o oral. Por esta razão, o poeta traz na voz o início e o meio de um diálogo que não acaba na feira livre, invade os lares, é letra e voz que permitem o letramento daqueles que atravessam essa tradição cultural que materializa a língua portuguesa em ambientes nordestinos. Nessa tradição, a escrita funciona como suporte de memória, manifestada pela voz. Zumthor (1993) explica que no momento da transmissão vocal o texto se fragmenta e tende ao inacabamento. A voz invade a letra e põe em xeque a lógica de um espaço fechado. Em A letra e a voz, o autor assinala a existência de três tipos de oralidade: a primária e imediata, que não apresenta nenhum contato com a escritura, é aquela das sociedades desprovidas dos sistemas de simbolização gráfica ou grupos isolados ou analfabetos; a oralidade mista, em que há uma parcial influência da cultura do escrito; a oralidade segunda, própria de uma cultura grafocêntrica, em que toda a expressão é marcada pela presença e pelo valor da letra.

Cabe ao professor de língua portuguesa, frente à iniciativa de propor atividades de atualização dos discursos contidos em produtos textuais de culturas de expressão popular, a exemplo do cordel, e em espaço escolar de ensino-aprendizagem de língua(gem), contextualizar os significados “[...] para o grupo [...] de onde se originou a proposta, para que o assunto não seja tratado como folclore, mas como elemento cheio de importância para a estruturação e manifestação da vida simbólica daquele grupo" (BRASIL/ PCN, 1998b, p. 156).

2 Muitas vezes a leitura é simulada. O cordelista memoriza a voz tecida em letra no folheto e faz crer ao interlocutor ora que ler o texto ora que improvisa o acontecimento discursivo que ocorre tradicionalmente em feiras livres do interior nordestino. 
A própria ideia de cultura que sustenta minhas reflexões de ações docentes para o âmbito escolar provém de Rodrigues (2009), que dialoga : com os PCN (BRASIL, 1998b, p. 132): "Cada cultura tem sua história, condicionantes, características, não cabendo qualquer classificação que sobre leve uma em detrimento de outra”.Isto é:

A cultura é o conjunto de códigos simbólicos reconhecíveis pelo grupo a partir dos quais se produz conhecimento: neles o indivíduo é formado desde o momento de sua concepção nesses mesmos códigos e, durante a infância, aprende os valores do grupo. Por intermédio deles é mais tarde introduzido nas obrigações da vida adulta, da maneira como cada grupo social as concebe. A cultura, como código simbólico, apresenta-se como dinâmica viva (BRASIL, 1998b, p. 132).

Nesses documentos constam as bases para o entendimento, pelo professor da Educação Básica, dos materiais humano e cultural que compõem a sociedade brasileira em formação escolar:

[...] todo e qualquer indivíduo nasce no contexto de uma cultura e, ao longo de sua vida, ajuda a produzi-la. Não existe homem sem cultura, mesmo que não saiba ler, escrever e fazer contas. É como se fosse possível dizer que o homem é biologicamente incompleto: não sobreviveria sozinho sem a participação das pessoas e do grupo que o gerou(BRASIL/PCN, 1998b, p. 132).

A concepção de cultura apresentada pelos documentos oficiais referidos, no tocante ao que propomos para o ensino da língua materna, em diálogo com a cultura de expressão popular nordestina, isto é, com a promoção do letramento escolar mediante folhetos de cordel, permite concluir que a cultura local, "Quando valorizada, reconhecida como parte indispensável das identidades individuais e sociais, apresenta-se como componente do pluralismo próprio da vida democrática”. Para o documento, “[...] fortalecer a cultura de cada grupo social, cultural e étnico que compõe a sociedade brasileira, promover seu reconhecimento, valorização e conhecimento mútuo, é fortalecer a igualdade, a justiça, a liberdade, o diálogo e, portanto, a democracia” (BRASIL/PCN, 1998b, p. 132). 
Frente ao quadro apresentado para a Educação Básica, com destaque para o processo de letramento escolar mediado por folhetos de cordel,fazse necessário compreender onde e quando o sujeito escreve ou fala, ou se escreve para simular uma fala, isto é, torna-se inerente desse processo conhecer sua cultura e os alicerces de sua tradição/memória.

$\mathrm{Na}$ esteira deste raciocínio e tendo como marco teórico o pensamento de Heath, Marcuschi (2001) explica que o evento de letramento, em qualquer ocasião, integra a natureza das interações dos participantes e seus processos interpretativos. São os usos da leitura e da escrita em contextos contínuos, reais, etnograficamente desenvolvidos e não isolados, que garantem a interação. A partir das ideias de Barton e Hamilton, Marcuschi (2000) formula o argumento de que os eventos de letramento são, em grande parte, atividades que têm textos escritos envolvidos, seja para serem lidos ou para se falar sobre eles. No entanto, estes eventos não são exclusivamente mediados por uma escrita sem a presença da fala. Uma carta pessoal, por exemplo, é um evento de letramento, já sua leitura com comentário é uma prática de letramento que envolve mais do que apenas a escrita. Dessa forma, os eventos de letramento são acontecimentos comunicativos mediados por textos escritos, mas não isolados do oral.

Quanto às práticas de letramento, Marcuschi (2000) explica que são os modos culturais, gerais de utilização do letramento pelas pessoas e se dão mediante eventos de letramento. As práticas de letramento são modelos que construímos para os usos culturais em que produzimos significados na base sociodiscursiva de acontecimento da leitura e da escrita. A carta pessoal, exemplo de um evento de letramento já mencionado, acontece como um fenômeno da escrita em diferentes contextos sociais e que possibilita diferentes letramentos aos sujeitos neles envolvidos, ao passo em que os próprios sujeitos interferem em novos eventos e práticas de letramento. Estas interferências são, em grande parte, mediadas pela voz, pela fala ${ }^{3}$. Nessa perspectiva,

[...] até mesmo os analfabetos, em sociedades com escrita, estão sob a influência do que contemporaneamente se

3 Apesar de ter conhecimento da distinção que é feita por alguns estudiosos que consideram fala e voz aspectos distintos da linguagem, em meus estudos não invisto em tais distinções. Tomo a linguagem em sua expressão tanto escrita quanto falada; e a voz como elemento acústico performático, multimodal (começa na boca e se prolonga pelo corpo) herdeira de uma tradição oral que tem na fala sua efetivação biológica e sociolinguística. 
convencionou chamar de práticas de letramento, isto é, um tipo de processo histórico e social que não se confunde com a realidade representada pela alfabetização. [...] o letramento não é o equivalente à aquisição da escrita. Existem 'letramentos sociais' que surgem e se desenvolvem à margem da escola, não precisando serem por isso depreciados (MARCUSCHI, 2001, p. 19).

Para o autor, dentre os contextos sociais da vida cotidiana onde escrita e oralidade ocorrem como eventos e práticas de letramento, o trabalho, a escola, a família, a vida burocrática, a atividade intelectual são apenas alguns dos exemplos de contextos em que a ênfase e os objetivos do uso da escrita são diversos. Há, todavia, espaços onde a palavra falada atravessa, propõe status e autoriza a produção do escrito. A fala é o animus da linguagem (ZUMTHOR, 1993). Mesmo no registro escrito, a palavra é pulsante, salta do texto aos olhos e permite que a escritura transcenda a frieza petrificante de um registro monológico.

Vê-se, assim, a relevância da relação entre linguagem e contexto social, em que a fala prevalece como prática discursiva de uma tradição cultural linguística de vários séculos. Hjelmslev (1975, p. 01) sustenta que a fala humana, palavra pronunciada, vocalizada, é uma inesgotável riqueza de múltiplos valores. Inseparável do homem, segue-o em todos os seus atos, sendo o instrumento modelador do pensamento, sentimentos, emoções, esforços, vontade e atos. $\mathrm{O}$ instrumento graças ao qual ele influencia e é influenciado. Base última e mais profunda da sociedade humana.

É por essa razão que os contadores de história são respeitados nas comunidades de tradição oral. Para Zumthor (1993, p. 67), eles são considerados mantenedores da memória da comunidade. $\mathrm{O}$ autor enfatiza o papel desses contadores que se assemelham com os cordelistas do Nordeste: intérpretes dos discursos atualizados por eles e produzidos por seus antepassados. São responsáveis por pronunciarem as palavras necessárias "a manutenção do laço social, sustentando e nutrindo o imaginário e confirmando os mitos”. Neste contexto, a voz do enunciador assume uma função coesiva e estabilizante, sem a qual o grupo social não poderia viver. A palavra viva, encarnada na voz, é a referência permanente e mais segura para a comunidade de onde ela provém. É memória. A 
: coerência de uma escritura, da inscrição do homem na história, pessoal : e coletiva. "A voz não cessa de cobrir e descobrir um sentido que ela ultrapassa, submerge, afoga, projeta e que parasita" (ZUMTHOR, 1993, p. 158). Movimento ondular, cíclico, progressivo e que caracteriza essa forma de expressão linguística,nos processos de letramento, a voz funda uma imanência do verbal, porque a palavra é laço e liga vidas. Falar é uma prática da tradição que a modernidade não busca mais superar em eventos de letramento contemporâneos, mas dela se espelhar em prol de um desenvolvimento global dos processos de significação alcançados pela linguagem multifacetada e dialogizante.

Desse raciocínio, pode-se considerar a natureza e a validezda imagem do contador de histórias na escola: narra acontecimentos numa poética de atualização discursiva que se dá por intermédio da voz. A partir de um poder criativo, adapta cada história ao espaço em que o interlocutor se insere. Deixa no instante do acontecimento enunciativo a marca de uma presença, sua subjetividade, pouco valorizada pelos primeiros estruturalistas e demais sujeitos que ainda reproduzem esse juízo de valor em espaços formais da Educação Básica. A escola se encarregou de disseminar "uma concepção de cultura uniforme, depreciando as diversas contribuições que compuseram e compõem a identidade nacional" (BRASIL/PCN, 1998b, p. 126). Por essa razão,

É bastante comum a expectativa de desempenho baixo em relação ao aluno proveniente das camadas economicamente menos favorecidas [...]. A situação de pobreza, manifesta na favelização das áreas urbanas e na precariedade da zona rural, ou na dificuldade de adaptação do filho do migrante, lamentavelmente tem sido um estigma para muitas crianças e adolescentes na escola. Algumas doutrinas pedagógicas concorreram para acentuar atitudes equivocadas por parte de educadores na escola. Teorias que afirmam a carência cultural, ainda que rejeitadas atualmente, deixaram marcas na prática pedagógica justificando o fracasso escolar única e exclusivamente pela 'falta de condições' dos alunos (BRASIL/PCN, 1998b, p. 126). 
Sigo na contramão dessa mentalidade propondo uma intervenção em sala de aula de língua portuguesa permeada por materiais textuais próprios de cada cultura, dasregionalidades que compõem a pluralidade cultural da nação brasileira. Sugiro tomar o cordel para dele/nele conduzir um trabalho com foco na análise/reflexão do texto/discurso. Estudar possibilidades de entrada no texto/linguagem, a partir da formulação de meios práticos frente às subjetividades de cada sala de aulacom o exame das modalidades da língua (ler, escrever, falar, analisar a língua).

Zumthor (1993) alerta para o fato de haver ainda muito preconceito entre intelectuais acerca da existência de um texto que traz a autoridade da voz e da importância do efeito vocal (do jogral, contador, leitor) sobre o ouvinte, mas a oralidade, em conjunto com outros recursos multimodais (o gesto, o olhar etc.), é de extrema relevância para a comunicação humana. O contador de histórias populares faz uso desses recursos no momento de sua performance,prende a atenção e cativa o público, porque é fato que "o ser humano natural não é escritor ou leitor [apenas], mas falante ouvinte" (HAVELOCK, 1995, p. 27). Para Zumthor (1993, p. 143), "Na medida em que o intérprete empenha assim a totalidade de sua presença com a mensagem poética, sua voz traz o testemunho indubitável da unidade comum. Sua memória descansa sobre uma espécie de 'memória popular' que não se refere a uma coleção de lembranças folclóricas, mas que, sem cessar, ajusta, transforma e recria".

$\mathrm{Na}$ tradição dos jograis, a palavra ganhava vida, era transmitida oralmente. $\mathrm{Na}$ performance do contador/cantador, a palavra era "reatualizada, reescutada, mais e melhor do que teria podido a escrita" (ZUMTHOR, 1993, p. 71). Era no momento de encontro entre narrador e ouvinte que se dava a relação semiotizante da palavra pulsante, viva, encarnada na história dos participantes desse acontecimento de linguagem. Havia ainda, e isso era imanente à performance, troca de olhares acompanhada de gestos que reforçavam e confirmavam o dito. Neste instante de interlocução, a palavra assumia sua forma propriamente ideológica, fazia história, significava. Isso demonstra como os jograis afetaram "profundamente a sensibilidade e as capacidades inventivas de populações que, de outro modo, nada teria aproximado" (ZUMTHOR, 1993, p. 71). 
Enxerga-se nessa lembrança cenas que poderiam ilustrar a performance profissional de muitos professores que atuam com a palavra em sala de aula. Temos em Zumthor (1993) a intuição de esboço de "método" de tratamento da linguagem que transcende a escritura monológica e que evidencia um pacto entre letra e voz: processo contínuo de relações dialógicas que se manifestam no espaço da enunciação.

Ressalta-se, ainda, que há particularidades inerentes à escritura e à voz. O leitor frente à atividade de desvendar os sentidos inerentes ao texto escrito completa-o a partir, unicamente, dos recursos textuais presentes. Por outro lado, na leitura da voz, no instante de interpretação do discurso oral, há uma participação mútua entre falante e ouvinte para a efetivação da compreensão do discurso pelo interpretante, uma vez que com o auxílio dos recursos de entonação, gestos e da forma que conduz sua performance, o falante condiciona o ouvinte a um entendimento mais próximo do enunciado. Além do mais, os recursos linguísticos utilizados na expressão oral podem ser modificados a cada atualização da palavra: fazem-se adequações cabíveis ao entendimento do interlocutor, que a cada instante se diferencia pelo acúmulo do interpretado. Tais recursos também são localizados na escrita, surgem como "imitações" da fala. Um exemplo é a forma direta de citação (aspas, travessão, recuo etc.), que não garante uma representação "fiel” da voz escriturada, haja vista serem oralidade e escritura modalidades diversas da língua, possibilidades linguísticas de expressão, e mesmo contínuos da linguagem humana, só que com recursos próprios para cada forma de interlocução.

Vê-se, assim, que não cabe julgar qual a modalidade de linguagem é a mais, ou menos, relevante para expressar os sentidos mediante gêneros textuais utilizados na cultura como prática social de comunicação/ informação/interação. Entretanto, mesmo após a primazia da escrita, não podemos ignorar a relevância da prática social de produzir linguagem no aqui e agora em que a fala é expressão mais imediata e promove menos incompletudes. Portanto, a escola não deve ignorar a importância da modalidade oral da língua,Benjamin (1994, p. 198)já elucidava que "entre as narrativas escritas, as melhores são as que menos se distinguem das histórias orais contadas pelos inúmeros narradores anônimos” e Monteiro Lobato, no Sítio do Picapau Amarelo, enfatizava os ensinamentos de 
Dona Benta que eram mediados pela oralidade. Zilberman (2001, p. 135) assinala que em Lobato "a escrita simula a fala, camuflando sua origem e : escondendo-se sob a máscara da audição", mas alerta que a mediação do oral tem como suporte o livro impresso, um truque bem-sucedido do autor: "O texto, produto da escrita e matéria de leitura, faz de conta que é dito, enquanto o leitor acredita estar ouvindo; da mesma maneira que ele pensa estar no Sítio, quando, na verdade, encontra-se numa forma de escola”. Para a autora, foi graças ao êxito desse procedimento que Monteiro Lobato formulou seu ideal de professor, traduzido por Dona Benta: "Mestra de qualidade, ela é igualmente boa e contumaz leitora, [...] permanentemente atualizada, fazendo os picapauzinhos cúmplices de sua prática cultural. Para dar certo, contudo, compete-lhe mascarar seus atributos: nada pode revelar a verdadeira face, para não perder o encanto - nem o texto se declarar leitura, nem o espaço se confessar sala de aula” (ZILBERMAN, 2001, p. 135).

Rojo (1995, p. 87) acentua a relevância do oral para o êxito do processo de letramento, o que se dá a partir de um olhar que possibilita enxergar os diferentes modos da participação dos sujeitos e de suas práticas discursivas orais e de produção de sentidos. A autora destaca que "[...] se a fala antecede ou tem precedência sobre a escrita, não é senão no sentido em que o [...] oral é o meio e a trama pelo qual todas as construções do propriamente humano são arquitetadas: a própria fala, o sujeito, o outro, o mundo para o sujeito, a fala à maneira da escrita (a fala letrada) e, finalmente como objeto do/no mundo, a própria escrita em sua materialidade”.

Seguindo a linha do raciocínio instituído pelos estudos de Heath, Terzi (1995, p. 91) sublinha que, tendo em vista o desenvolvimento da língua, o oral e o escrito se suportam e se influenciam mutuamente. Para ela, nos meios letrados onde a escrita é componente da vida cotidiana da família, a construção das duas modalidades se dá de forma simultânea.Dessa forma, a autora endossa a tese que defendoe que sinaliza para propostas de ensino de língua alicerçadas em práticas e eventos de letramento mediados pela influência da oralidade na construção da escrita. Creio que esse trabalho escolar só pode se tornar possível se eliminados os preconceitos de que a modalidade oral da linguagem é desprovida de sistematização, imprópria para o uso formal da língua oficial e que, por essa razão, deve ficar em casa, pois pode "poluir" os textos de nossos alunos. 
Mesmo diante dos fatos supracitados, a escola ainda desconsidera as características de letramento do povo brasileiro. Ignora o fato de que "cada comunidade tem sua própria orientação de letramento" e que caberia à escola considerar que "o tipo de orientação da classe média não pode ser tomado como modelo universal” (TERZI, 1995, p. 101). Os PCNdenunciam a frequente ignorância daqueles que não concebem a multiplicidade de letramentos e a própria valorização da diversidade cultural do povo brasileiro: "Freqüentemente, [...] esse processo complexo presente na vida brasileira é ignorado e/ou descaracterizado. $\mathrm{Na}$ escola, onde a diversidade está presente diretamente naqueles que constituem a comunidade, essa presença tem sido ignorada, silenciada ou minimizada. São múltiplas as origens da omissão com relação à Pluralidade Cultural” (BRASIL/PCN, 1998b, p. 125).

Diante da cena instituída, cabe-nos ter a consciência de que "A diversidade marca a vida social brasileira. Diferentes características regionais e manifestações de cosmologias ordenam de maneiras diferenciadas a apreensão do mundo, a organização social nos grupos e regiões, os modos de relação com a natureza, a vivência do sagrado e sua relação com o profano" (BRASIL/PCN, 1998b, p. 125). Cada grupo de alunos deve ser letrado a partir de eventos e práticas de letramento que são considerados legítimos pelos sujeitos envolvidos nesse processo (alunos, pais, familiares e amigos). A leitura de textos de tipos diversos e com objetivos específicos permite criar situações que envolvem a utilização da escrita pelo letrando como, por exemplo, anotação de recado, leitura de um bilhete, acompanhamento da Bíblia, a prestação de contas, correspondência, propagandas, preenchimento de cheque solicitado por alguém da família, preenchimento de cupons etc. Isso tudo perpassado pela influência da oralidade como engrenagem para a construção do texto escrito. Dessa forma, o aluno passaria a relacionar a língua escrita com a oral, redefinindo a ideia de escrita que se efetiva no cotidiano das cidades.

Com essa tomada de ação, o professor estaria quebrando a barreira que separa oral do escrito, e que muito dificulta no processo de aquisição/ aperfeiçoamento da língua pela comunidade escolar. $\mathrm{O}$ aluno passaria, então, a entender o escrito como outra forma de falar e fazer sentido, de se expressar em sua comunidade. Motivar-se-ia, então, a percorrer o caminho 
da escrita permeado pela voz. Esse processo de letramento mediado pela voz pode se dar, explica Terzi (1995, p. 105), a partir de três momentos: quando há a retomada da linguagem do dia a dia na interação com o adulto; quando as crianças começam a fazer sentido do texto na leitura individual, identificando no texto as palavras já conhecidas na fala e questionando aspectos que são próprios da escrita; e quando utilizam, na reconstrução do texto lido, o processo de construção textual próprio da interação face a face.

No processo de letramento das crianças descritas em Terzi (1995, p. 107), “a retomada da língua oral antes da atribuição de sentido ao texto escrito parece justificar-se pelo fato de a língua oral constituir a experiência lingüística que já possuíam”. Considero que com a retomada da linguagem do cotidiano do aluno na interação face a face em processos de letramento escolar, dar-se-ia início na escola a atribuição de um sentido à escrita: o texto passaria a ser o objeto sobre o qual se fala. Assim, os aprendizes estabeleceriam as primeiras relações entre o oral e a escrita, fazendo e extraindo sentido em textos; e perceberiam que é possível fazer a correspondência entre as modalidades da língua, de maneira natural e sem obstáculos em suas travessias pelas práticas linguísticas. Estar-se-ia, assim, atentando para a necessidade de se "trabalhar linguagens do mundo contemporâneo, em sua interação na vida cotidiana” (BRASIL, 1998b, p. 158).

\section{CONCLUSÃO}

Os argumentos apresentados neste texto reforçam a ideia de uma possibilidade metodológica para o desenvolvimento de planos de ação docente com foco no ensino-aprendizagem de modalidades da língua por parte de alunos em processo de letramento escolar. Alvitro um trabalho com a linguagem em que o aluno interage constantemente com parceiros do plano discursivo de sua localidade - professor, colegas, pais e familiares -, a partir da mediação do oral com textos escritos, e mesmo que simulam eventos orais de interação verbal, neste caso, destaqueiofolheto de cordel,elemento textual e discursivo de grande relevância para a experiência linguística do "aprendiz da linguagem" que circula em cidades nordestinas. 
A atenção ao fenômeno da oralidade, aspecto linguístico muito presente na escritura dos cordéis,permite a compreensão,por crianças e adultos em processo de letramento, do funcionamento de uma escrita que figura no plano social como representação da fala. A legitimação dessa tradição, a partir de um processo de ensino-aprendizagem de língua materna, permite-nos despertar para o fato de que "Tratar da tradição oral de diferentes grupos étnicos e culturais terá, assim, tanto um sentido de exploração de linguagem quanto de conhecimento de elementos ligados a diferentes tradições culturais” (BRASIL/PCN, 1998b, p. 156-157).

Reafirmo a assertiva de que a voz possui papel decisivo no processo de aquisição do escrito. A influência do oral frente ao processo de letramento propicia a garantia de efetivação da tecnologia escrita da linguagem por sujeitos que interagem socialmente em práticas discursivas orais e escritas da vida cotidiana. Mediante o exame/estudo da materialidade linguística/ textual do cordel, professores ealunos se permitem perceber o equilíbrio entre uma memória escrita e uma memória oral, evidenciadas em folhetos de feira, em que a memória oral se sobressai, demonstrando o valor dessa modalidade da língua portuguesa. A escrita se coloca, assim, como um artifício em prol da manutenção da voz no texto, selandouma tradição que se renova no universo em que o folheto figura como objeto de memória e para a efetivação de identidadesdo povo brasileiro.

O cordel é o grande mediador dessa prática discursiva/social. No Nordeste, é ponte, meio de interação entre sujeitos que se encontram coerentemente integrados pela relação que propicia na cultura, na história, na sociedade brasileira. Diante disso, expressões como tradição, cultura e memória, elementos que se confundem/entrecruzam, precisam ser constantemente enfatizadas na tarefa de mediar o ensino de língua(gens) por professores que atuam na Educação Básica, bem como dos formadores de professores, principalmente quando se trata de um território como o brasileiro, composto por sociedades pluriétnicas/pluriculturais.

Essa realidade deve ser assistida pelos profissionais da escola, a partir da conscientização de que a formação cidadã de nossos alunos pressupõe o desenvolvimento das capacidades de: i) "compreender a memória como construção conjunta, elaborada como tarefa de cada um e de todos, que contribui para a percepção do campo de possibilidades individuais, 
coletivas, comunitárias e nacionais"; ii) "valorizar as diversas culturas presentes na constituição do Brasil como nação, reconhecendo sua : contribuição no processo de constituição da identidade brasileira”; e iii) "reconhecer as qualidades da própria cultura, valorando-as criticamente, enriquecendo a vivência de cidadania” (BRASIL/PCN, 1998b, p. 143).

Entretanto, há uma ideia "veiculada na escola de um Brasil sem diferenças”, difundida com o apoio dos livros didáticos que neutralizam "as diferenças culturais" e subordinam "uma cultura à outra"; concepção de cultura equivocada, pois deprecia "as diversas contribuições que compuseram e compõem a identidade nacional" (BRASIL/PCN, 1998b, p. 126).Nas palavras ordenadas para a composição desta "fala", busquei sustentar a prerrogativa de que este é um desafio que se faz ao professor que atua com a linguagem em espaços institucionalizados de ensino:espera-se dele sensibilidade e postura plásticas para se adaptar a realidade do aluno em processo de letramento múltiplo.

\section{REFERÊNCIAS BIBLIOGRÁFICA}

ABREU, Márcia. Histórias de cordéis e folhetos. Campinas: Mercado de Letras, 1999.

BAKHTIN, Mikhail (VOLOSHINOV, V. N.). Marxismo e filosofia da linguagem. 10. ed. São Paulo: Hucitec, 2002.

BATISTA, Sebastião Nunes. Antologia da Literatura de Cordel. Natal: Ed. Fundação José Augusto, 1977.

BENJAMIN, Walter. Magia e técnica, arte e política: ensaios sobre literatura e história da cultura. 7. ed. São Paulo: Brasiliense, 1994.

BRANDÃO, Adelino. Crime e castigo no cordel. Rio de Janeiro: Presença, 1990.

BRASIL. Ministério da Educação. Secretaria de Educação Fundamental. Parâmetros Curriculares Nacionais: terceiro e quarto ciclos do ensino Fundamental de Língua Portuguesa. Brasília: MEC, 1998a. 
: BRASIL. Ministério da Educação. Secretaria de Educação

: FundamentalParâmetros Curriculares Nacionais: Pluralidade Cultural. Brasília: MEC, 1998b.

BRITO, Percival Leme. Leitor interditado. In: MARILDES, Marinho \& SILVA, Ceris Ribas da (Org.). Leiturasdo professor. São Paulo: Mercado de Letras, 1998.

CASCUDO, Luís da Câmara. Dicionário do folclore brasileiro. 6. ed.BH: Itatiaia, 1988.

. Os cinco livros do povo.João Pessoa: Universitária/UFPB, 1994.

GERALDI, João Wanderley. Portos de passagem. 4. ed. São Paulo: Martins Fontes, 1997.

- A aula como acontecimento. São Carlos, SP: Pedro e João Editores, 2010.

HAVELOCK, Eric. A equação oralidade-escritura: uma forma para a mente moderna. In: OLSON, David. Cultura e oralidade. São Paulo: Ática, 1995.

HJELMSLEV, Louis. Prolegômenos a uma teoria da linguagem. SP: Perspectiva, 1975.

LIMA, M. V. de. Narradores do Padre Cícero: do auditório à bancada. Fortaleza: Programa Editoral / UFC, 2000.

KLEIMAN, Angela B. (Org). Os significados do letramento: uma nova perspectiva sobre a prática social da escrita. São Paulo: Mercado de Letras, 2001.

MARCUSCHI, Luiz A. Gêneros textuais: o que são e como se constituem. Recife: Ed. da UFPE, 2000.

- Da fala para a escrita: atividades de retextualização. 2. Ed. SP: Cortez, 2001.

MEYER, Marlyse. Autores de cordel.São Paulo: Abril Cultural,1980. 
PROENÇA, Ivan Cavalcanti. A ideologia do cordel.2. ed. Rio de Janeiro: Brasiliense, 1977.

RODRIGUES, Linduarte Pereira. O apocalipse na literatura de cordel: uma abordagem semiótica. João Pessoa: UFPB, 2006. (Dissertação de mestrado)

- Vozes do fim dos tempos: profecias em escrituras midiáticas. João Pessoa: UFPB, 2011. (Tese de doutorado)

ROJO, Roxane Helena Rodrigues. Concepções não-valorizadas de escrita: a escrita como "um outro modo de falar".In: KLEIMAN, Angela B. (Org.) Os significados do letramento: uma nova perspectiva sobre a prática social da escrita. São Paulo: Mercado de Letras, 1995.

TERZI, Sylvia Bueno.A oralidade e a construção da leitura por crianças de meios iletrados.In: KLEIMAN, Ângela B. (Org.) Os significados do letramento: uma nova perspectiva sobre a prática social da escrita. São Paulo: Mercado de Letras, 1995.

ZILBERMAN, Regina. Leituras sobre o professor: o que diz a literatura brasileira. In: MARINHO, Marildes. (Org.) Ler e navegar. São Paulo: Mercado de letras, 2001.

ZUMTHOR, Paul. A letra e a voz. São Paulo: Companhia das Letras, 1993. 